\title{
Retaining Talent: The Role of the Personal and Contextual Factors
}

\section{Talat Islam*, Zeshan Ahmer ${ }^{* *}$ and Naeem Mushtaq ${ }^{* * *}$}

\begin{abstract}
Earlier studies have focused on the attitudinal and behavioral aspects of employee turnover. However, this study empirically investigates the contextual (i.e. job complexity, developmental feedback and perceived organizational support) and personal (i.e. proactive personality and core self-evaluations) aspects in order to elucidate turnover intention among the private sector universities of Pakistan. The study used a questionnaire-based survey that was circulated amongst the faculty members of the private universities, and 758 responses were used for the final data analysis. Moreover, the structural equation modeling was applied and revealed that core self-evaluation, developmental feedback, job complexity and perceived organizational support are negatively associated with turnover intention. However, the element of proactive personality was found to have a nonsignificant association with turnover intention. This study has theoretical and practical implications for universities and recruitment departments.
\end{abstract}

Keywords: Developmental feedback, perceived organizational support, job complexity, proactive personality, core self-evaluations.

JEL Classification: M10, M12.

\section{Introduction}

The role of Human Resource Development (HRD) is essential to motivate, attract and retain talented employees (Wagstaff, del Carmen Triana, Kim, \& Al-Riyami, 2015). Talented employees do not only lead organizations towards competitiveness in the long run, but these employees are also critical factor for the overall success of an organization (Islam \& Tariq, 2018). Thus, retention of employees with the relevant skills

\footnotetext{
* Assistant Professor, Institute of Business Administration, University of the Punjab, Lahore, Pakistan. ${ }^{* *}$ Assistant Professor, Institute of Business Administration, University of the Punjab, Lahore, Pakistan. *** MS Scholar, Hailey College of Banking \& Finance, University of the Punjab, Lahore, Pakistan.
} 
and knowledge is essential for an organization. For decades, identifying the turnover intention has remained an inspiring catch-all in the eyes of researchers and policymakers, as it is considered as the strongest predictor of turnover (Islam, Khan, Ahmad, Ali, \& Ahmed, 2014; Kim \& Hyun, 2017; Park, 2019).

Literature has suggested some pivotal theories on turnover. For instance, the organizational equilibrium theory (OET) of turnover, (March \& Simon, 1958), is considered to be the basis for most of the theories that have been developed on the concept of turnover. This theory focuses on maintaining a balance between the employees' input into an organization and the incentives given to them by the organization. Willingness to leave, and perceived ease of movement are the main predictors of this particular balance. In this context, when extending the OET, Mobley (1977) introduced the concept of job search behaviors (i.e. job satisfaction), and withdrawal cognition (i.e. turnover) in a model. In addition to this, the expectancy theory of motivation became the base for Porter and Steers's (1973) met expectation theory (MET) of turnover. The expectancy theory proposes that "work motivation is dependent upon the perceived association between performance and outcomes, and that the individuals modify their behavior based on their calculation of anticipated outcomes" (Chen \& Fang, 2008, p. 155).

Ample literature has attempted to identify the predictors of turnover, but the identification of actual predictors of turnover is still a question mark. Researchers, therefore, have suggested studying the turnover intention, rather than the actual turnover (Islam, 2014; Islam et al., 2019). In addition to this, without understanding the causes of employees' turnover intention, retaining skilled employees would be merely an unrealized dream (Joo, Hahn, \& Peterson, 2015). According to Mor Barak, Nissly, and Levin (2001), professional perceptions (i.e. organizational commitment etc.), demographical characteristics (i.e. workrelated and personal) and organizational conditions (i.e. organizational culture and compensation etc.) are three of the major antecedents of turnover intention. However, the contextual and personal factors are less focused on aspects in this regard (Joo et al., 2015).

Previous studies considering the impact of personal factors on employees' turnover intention have focused on the Big Five personality 
factors (Allen, Weeks, \& Moffitt, 2005), except the work done by Barrick and Mount (1996). However, emerging personality factors have not frequently been examined (Joo et al., 2015). On the other hand, organizational level factors have not been focused on examining the individual's decision on turnover intention (Griffeth, Hom, \& Gaertner, 2000). Considering the importance of organizational and contextual factors as determinants of employees turnover intention, this study aims to focus on developmental feedback (DFB), job complexity (JC) and perceived organizational support (POS) (from contextual factors), and proactive personality (PP) and core self evaluation (CSE) (from personal factors), as the main predictors of employees' turnover intention.

This study tested the proposed hypotheses on the faculty members of private universities. The faculty members are required to publish research along with their teaching assignments, which demand extra efforts (Islam, 2019). Given this, the university's management (especially in case of private universities) forget to keep a focused approach towards the workload of their faculty (Ahmad \& Islam, 2018). This not only creates stress, but also evokes their intentions to switch (i.e. turnover intention). Thus, these issues generate the need to study turnover intention among faculty members of intuitions where higher education is offered.

The findings of this study would contribute in several ways. Theoretically, the findings add to the existing limited literature on organizational expectancy theory, by incorporating unattended contextual and personal factors. Practically, this study will help university management, and higher education authorities in developing strategies to retain their faculty members. The next section of the study covers the theoretical support and hypotheses.

\section{Theoretical Underpinnings and Hypotheses Development}

Certain human behaviors are the result of one's perception and personality characteristics. This study assumes that both the aspects are important in order to investigate, and understand their turnover intention better. Therefore, the study considers PP and CSE as personality characteristics, and POS, JC, and DFB as contextual factors. Furthermore, this study is supported by various turnover theories (explained in the introduction), such as the organizational support theory (OST) and the social 
exchange theory (SET). According to SET, "there exists some exchange relations among parties and when one party receives something of value it tries to reciprocate" (Blau, 1964, p. 81). While, the OST states that, "when employees in an organization feel that their organization care their values, they reciprocate it" (Eisenberger, Huntington, Hutchison, \& Sowa, 1986).

\subsection{Proactive Personality (PP) and Turnover Intention (TI)}

The "proactive personality" is an individual's ability to affect environmental changes and conquer constrictions by situational forces (Bateman \& Crant, 1993). According to Crant, (2000, p. 436), proactive behavior means, "taking the initiative in improving current circumstances or creating new ones; it involves challenging the status quo rather than passively adapting to present conditions". Individuals with a proactive approach are in continuous search to identify the opportunities. When they get successful in identifying the desired opportunities, they try to manipulate the environment in their favor, in order to achieve the desired outcomes. On the other hand, individuals with less proactive personality let the things happen first and then try to adapt to the change (Bateman \& Crant, 1993). Thus, proactive individuals are focused on long-term goals and remain flexible as they have organizational consequences to consider (Parker, Williams, \& Turner, 2006).

Moreover, proactive individuals are more concerned about their career development and growth, as compared with less proactive individuals who have confidence in their abilities. Allen et al. (2005) noted that proactive personalities tended to be risk takers. In another study, Crant (2000) argued that proactive personalities are more likely to take the initiative and have a greater ability to find alternate ways, and because of this such personalities have more intentions to switch their job. Thus, this study hypothesizes a positive association between PP and TI in the following hypothesis.

Hypothesis 1: PP will be positively associated with TI.

\subsection{Core Self-evaluations (CSE) and Turnover Intention (TI)}

A personality trait that includes an individual's subconscious, their own control, their own ability and fundamental evaluations about 
themselves is referred to as core self-evaluation (Judge, Erez, Bono, \& Thoresen, 2003). CSEs comprises of four dispositional characteristics i.e. locus of control, self-efficacy, emotional stability and self-esteem (Judge, 1997). Thus, the characteristics of positive self-concept depend upon the higher CSEs (Judge et al., 2003).

According to Chang, Ferris, Johnson, Rosen, and Tan (2012), initially CSEs were assumed to enhance an individual's job satisfaction, and many of the researchers identified a positive relationship between the same (Lyons, 2015; Wu \& Griffin, 2012). As job satisfaction remained a strong predictor of TI for decades (Islam, 2014), therefore, examining how CSEs impact an individual's intention to leave the organization would be of worth. Individuals with low CSE have high concerns, with the negative aspects of the environment. Whereas, individuals with high level of CSEs have less concern with the negative aspects of their working conditions (Chang et al., 2012). Based on the above arguments, this research hypothesizes a negative link between CSEs and TI in the following hypothesis.

Hypothesis 2: CSEs will be negatively associated to TI.

\subsection{Job Complexity (JC) and Turnover Intention (TI)}

Job design is a strong predictor of employees' performance, motivation, and attitudes. According to Hackman and Oldham (1980), the job characteristics model task identity, skill variety, task significance, feedback, and autonomy are the five basic dimensions of jobs. For more complex jobs, individuals don't only need to possess complex task-related skills (Chung-Yan, 2010). Therefore, job complexity should be considered as a positive aspect of the work.

This notion is supported by the meta-analysis of Humphrey, Nahrgang, and Morgeson (2007), as they demonstrated a positive impact of job complexity on various job outcomes (i.e. employees' organizational commitment, internal motivation for work, job performance, job involvement, and job satisfaction). In addition, JC negatively predicts employees' intention to leave (Grebner et al., 2003). According to Man and Lam (2003), individuals need to find new methods and approaches to accomplish challenging tasks, and such activities might adhere individuals 
to be with the current organization. The following hypothesis postulates a positive relationship between JC and TI.

Hypothesis 3: JC will be positively associated to TI.

\subsection{Perceived Organizational Support (POS) and Turnover Intention (TI)}

According to Eisenberger et al. (1986), POS is the employees' perceptions of being cared for by their organization. The concept is based on the theory of organizational support that is laid on the foundations of the social exchange theory (Blau, 1964), and reciprocity norms (Gouldner, 1960). This theory states that, when employees perceive that their organization considers their socio-emotional well-being as its basic premise, they reciprocate with a high level of loyalty, commitment, job satisfaction, and less intention of leaving the organization (Islam, Ahmad, Ali, Ahmed, \& Bowra, 2013; Islam, Ahmed, \& Ahmad, 2015; Joo et al., 2015). Conversely, employees when feeling that their organization is not treating them well, tend to find and explore other job opportunities. In a recent meta-analysis, Ahmad and Allen (2015) confirmed a negative relationship between POS and TI. Thus, this study hypothesizes that a negative link exists between POS and TI, in the following hypothesis.

Hypothesis 4: POS will be negatively associated to TI.

\subsection{Development Feedback (DFB) and Turnover Intention (TI)}

According to Zhou (2003), a supervisor's useful and helpful information to its subordinates for their development and learning on the job is referred to as developmental feedback. In developmental feedback, supervisors provide a direct report of their supervisees, which contains their job performance related information without any pressure. Hence, it is a future-oriented approach. The developmental feedback approach is opposite to the traditional performance feedback approach, where information is provided at the completion of a specific task. Therefore, such kind of information not only enhances an individual's intrinsic motivation, but also leads to a development of their interest in the given tasks (Zhou, 2003).

Supervisors' developmental feedback tends to motivate newcomers to work with devotion and passion (Li, Harris, Boswell, \& Xie, 2011). In 
addition, this approach provides employees' with the learning facilities for grooming and development (Islam, 2019; Joo \& Park, 2010). When employees feel that they are given learning and grooming opportunities, they tend to stay with their organization. Thus, this study proposes a negative relationship between DFB and TI in the following hypothesis.

Hypothesis 5: DFB will be negatively associated to TI.

Figure 1: Theoretical Model

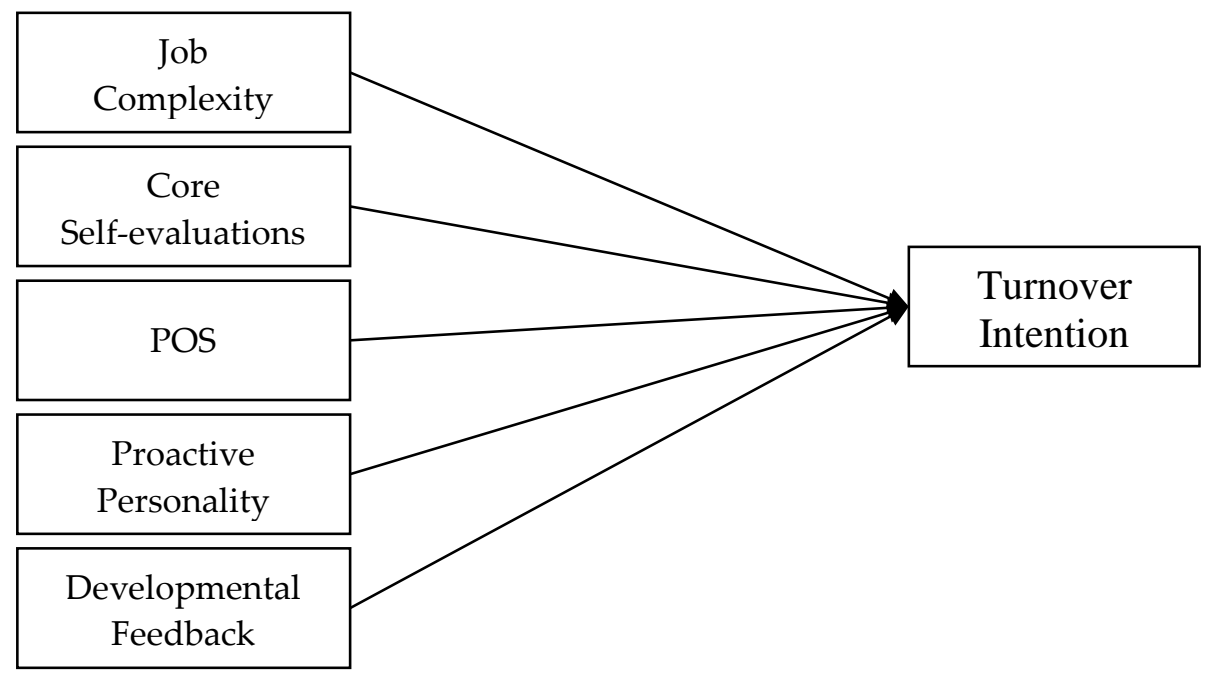

\section{Methods}

The faculty members of the private sector universities of Pakistan were the participants of this study. The main reason to consider the private universities was due to more workload and demand of extra work on their part, without caring for their faculty member. It was assumed that this may develop turnover intention (Islam, 2019). According to HEC, 74 private universities with 10,104 faculty members are operating in the country (www.hec.gov.pk). The study used a multi-stage sampling technique. At the first stage 21 universities with 4721 faculty members, located in the capital cities of the provinces, were randomly selected. In the second stage, using convenience sampling, a total of 1100 questionnaires were distributed, of which 758 were received (after excluding 65 as incomplete and outliers). The study distributed 1100 questionnaires, considering the low response rate of the studies conducted on faculty members (Ahmad \& 
Islam, 2018). The majority of the participants of this study were male $(78.10 \%)$, in their thirties (36.50\%) with the current work experience of 2-5 years $(28.80 \%)$, and an overall job experience of $6-10$ years $(30.60 \%)$.

\subsection{Measures}

A questionnaire comprised of six measures was distributed amongst the respondents. They were requested to record their responses on "a 5Point Likert scale ranging from 1-Strongly disagree to 5-Strongly agree".

\subsubsection{Proactive Personality (PP)}

A shortened version of Bateman and Crant (1993) was used to measure the proactive personality aspect. This version comprises of a 10item scale (Seibert, Crant, \& Kraimer, 1999). This study adapted the same scale, and noted 0.81 as its level for internal reliability. A sample item included "I am constantly on the lookout for new ways to improve my life".

\subsubsection{CSES}

Judge et al. (2003) developed a 12-item scale in order to examine CSEs based on self-efficacy, self-esteem, emotional stability and locus of control. Using the same scale, this study found the scale reliable with a value of 0.79 . A sample item included "I determine what will happen in my life".

\subsubsection{POS}

Eisenberger et al. (1986) introduced a scale to measure employees' perception of organizational support, and its shortened six-item scale was used by Ahmed, Khairuzzaman Wan Ismail, Mohamad Amin, and Islam (2014). After using this shortened scale, this study noted its internal reliability as 0.85 . A sample item included "my organization appreciates my contribution".

\subsubsection{Job Complexity}

Hackman and Oldham (1980) developed a scale to measure job characteristics including autonomy, task significance, task identity, feedback, and skill variety. Of which Joo et al. (2015) used a six-item scale containing autonomy and task significance, which are more relevant to job complexity. 
This study also used the six items scale and found the scale reliable at the level of 0.83. A sample item included "This job gives me considerable opportunity for independence and freedom in how I do the work".

\subsubsection{DFB}

A three-item scale was used to measure the developmental feedback which was originally developed by Zhou (2003). Using the same scale, an internal consistency of 0.78 was observed. A sample item included "My supervisor provides me with useful information on how to improve my job performance".

\subsubsection{TI}

For the purpose of this study, Mobley, Mobley, Horner, and Hollingsworth's (1978) three-item scale of TI was used. This scale showed that the internal reliability came out to be at a value of 0.87 . A sample statement is "I frequently think of leaving this organization".

\section{Results}

The Structural Equation Modeling (SEM) was applied in this study. According to Byrne (2010), SEM should be used in two-stages, as it reduces the interactional effects of structure models. First, the study fulfills the basic assumptions of SEM, and data was examined regarding outliers, missing values, and correlation (Hair, Black, Babin, \& Anderson, 2010). The correlation was applied to identify the significant association between demographical characteristics and observed variables, where all the demographical variables were found to have a non-significant association with the observed variables (see Table 1). Therefore, the demographical variables were not treated as control variables in testing hypotheses (Hair, Black, Babin, Anderson, \& Tatham, 2006).

The values of the Table 1 show that CSE, DFB, POS and JC have a negative correlation with turnover intention (i.e. $r=-0.21,-0.24,-0.28 \&-0.27$ respectively), whereas a non-significant association is examined between proactive personality and turnover intention. In this regard, the other variables were found to have a positive and significant association with each other. Moreover, the internal reliability of all the variables was above 0.70 . 
Table 1: Correlation Analysis

\begin{tabular}{lrrrrrrrrrr}
\hline Variables & 1 & 2 & 3 & 4 & 5 & 6 & 7 & 8 & 9 & 10 \\
\hline 1. Age & -- & & & & & & & & & \\
2. Gender & $.29^{*}$ & -- & & & & & & & & \\
3. Current_exp. & $.55^{* *}$ & $.42^{* *}$ & -- & & & & & & & \\
4. Total_exp. & $.49^{* *}$ & $.51^{* *}$ & $.26^{* *}$ & -- & & & & & & \\
5. CSE & .020 & .001 & -.046 & .028 & $(.79)$ & & & & & \\
6. PP & .004 & .009 & .026 & .031 & $.42^{* *}$ & $(.81)$ & & & & \\
7. POS & .006 & .021 & -.036 & .007 & $.14^{*}$ & $.25^{* *}$ & $(.85)$ & & & \\
8. DFB & .015 & .050 & .049 & .068 & $.31^{* *}$ & $.29^{* *}$ & $.39^{* *}$ & $(.78)$ & & \\
9. JC & .090 & .071 & .067 & .056 & $.37^{* *}$ & $.41^{* *}$ & $.33^{* *}$ & $.40^{* *}$ & $(.83)$ & \\
10. TI & .004 & .099 & .045 & .076 & $-.21^{* *}$ & .14 & $-.28^{* *}$ & $-.24^{* *}$ & $-.27^{* *}$ & $(.87)$ \\
\hline
\end{tabular}

Note: "CSE $=$ core self-evaluations, $\mathrm{PP}=$ proactive personality, $\mathrm{POS}=$ perceived organizational support, $\mathrm{DFB}=$ developmental feedback, JC= job complexity, $\mathrm{TI}=$ turnover intention, ${ }^{* *} \mathrm{P}<.001,{ }^{*} \mathrm{P}<.05,(\mathrm{)})$ Internal reliability, $\mathrm{N}=359 "$.

\subsection{Assessment of Uni-dimensionality}

First, the study examined the Confirmatory Factor Analysis (CFA) in order to examine the uni-dimensionality of the items. The main reason to apply CFA was that the study had used adapted scales (Byrne, 2010). The study used the following indices for the goodness-of-fit of Byrne (2010) as shown in Table 2. The researcher had to make some modifications as per the instructions of Hair et al. (2010). After modifications of the values were found as: $x^{2}=437.753, d f=153, x^{2} / d f=2.86, \mathrm{CFI}=0.962, \mathrm{GFA}=0.946, \mathrm{AGFA}=$ 0.929 , NFI $=0.931$, RMSEA $=0.045$.

\section{Table 2: Goodness-of-Fit Indices}

\begin{tabular}{llc}
\hline Model Fit & Full Name & Standard Value \\
\hline$x^{2} / d f$ & "Chi-Square" & $\leq 3$ \\
CFI & "Comparative Fit Index" & $\geq 0.90$ \\
GFI & "Goodness of Fit Index" & $\geq 0.90$ \\
AGFI & "Adjusted Goodness of Fit Index" & $\geq 0.90$ \\
NFI & "Normed Fit Index" & $\geq 0.90$ \\
RMSEA & "Root Mean Square Error of Approximation" & $\leq 0.08$ \\
\hline
\end{tabular}

The study also examined the values of loading for each item used in this study (see Table 3). Following the criteria given by Hair et al. (2010), the study noted that loading values were above 0.50 for all the observed variables of the study. In addition, the "convergent and discriminant validity were examined through the values of composite reliability $(\mathrm{CR})$ 
and average variance extracted (AVE)". The values in Table 3 also show that the values of AVE were well above 0.50 , and the values of $C R$ were well above 0.60 (Byrne, 2010), hence, the data has both the validities.

\section{Table 3: Loading, Reliability and Validity}

\begin{tabular}{lccccccccc}
\hline Variable & Loading & CR & AVE & $\alpha$ & Variable & Loading & CR & AVE & $\alpha$ \\
\hline PP1 & 0.69 & & & & CSE1 & 0.76 & & & \\
PP2 & 0.78 & & & & CSE2 & 0.85 & & & \\
PP3 & 0.76 & & & & CSE4 & 0.82 & & & \\
PP4 & 0.88 & & & & CSE5 & 0.80 & & & \\
PP5 & 0.83 & & & & CSE6 & 0.76 & & & \\
PP6 & 0.75 & 0.63 & 0.6 & 0.81 & CSE7 & 0.79 & 0.69 & 0.61 & 0.79 \\
PP7 & 0.68 & & & & CSE8 & 0.91 & & & \\
PP8 & 0.79 & & & & CSE9 & 0.82 & & & \\
PP9 & 0.75 & & & & CSE10 & 0.84 & & & \\
PP10 & 0.82 & & & & CSE11 & 0.86 & & & \\
JC1 & 0.88 & & & & CSE12 & 0.77 & & & \\
JC2 & 0.91 & & & & POS1 & 0.81 & & & \\
JC3 & 0.86 & & & & POS2 & 0.72 & & & \\
JC4 & 0.74 & 0.72 & 0.66 & 0.83 & POS3 & 0.64 & 0.61 & 0.56 & 0.85 \\
JC5 & 0.78 & & & & POS4 & 0.87 & & & \\
JC6 & 0.69 & & & & POS5 & 0.67 & & & \\
DFB1 & 0.88 & & & & POS6 & 0.74 & & & \\
DFB2 & 0.89 & 0.79 & 0.75 & 0.78 & TI1 & 0.86 & & & \\
DFB3 & 0.83 & & & & TI2 & 0.84 & 0.71 & 0.69 & 0.87 \\
& & & & & TI3 & 0.79 & & & \\
\hline
\end{tabular}

Note: "CSE= core self-evaluations, $\mathrm{PP}=$ proactive personality, $\mathrm{POS}=$ perceived organizational support, $\mathrm{DFB}=$ developmental feedback, $\mathrm{JC}=$ job complexity, $\mathrm{TI}=$ turnover intention".

\section{Findings and Discussion}

In order to test the hypotheses, we deployed the second-stage of SEM (Byrne, 2010). This study examined structural coefficients for the hypotheses testing, and the results showed the statistical significance of all the regression coefficients (i.e. $\mathrm{t}<1.98$ ). Moreover, the theoretical model of the study was found to have a good fit "(i.e. $x^{2}=543.213, d f=218, x^{2} / d f=2.49$, $\mathrm{CFI}=0.932$, GFA=0.945, AGFA $=0.908$, NFI $=0.918$, RMSEA $=0.039$ )" as compared with the cut-off values of the fit indices (see Table 2).

This empirical investigation aimed to examine the contextual and personal aspect's impact on employees' intention of turnover. Where PP 
and CSEs were considered from personal factors, and POS, JC and DFB were considered from contextual factors. The study found that both personal and contextual factors significantly, and negatively associated with TI, except proactive personality.

On the other side, a few of the previous studies have noted that certain demographical characteristics (e.g. tenure and age) have a significant association with the turnover intention (Lee \& Cho, 2013). However, in this study, all the demographical variables were noted to have a non-significant association with observed variables.

The study noted a negative and significant association between CSEs and TI $\left(\beta=-0.24^{* *}\right)$. This result is in line with the meta-analysis of Chang et al. (2012). Therefore, the study concluded that individuals with high CSEs are less concerned with their working conditions and tend to stay with their organization. While the study found a non-significant association between PP and TI $(\beta=0.14)$, this study assumed that individuals who possess a proactive personality are risk takers and don't hesitate to take the initiative (Allen et al., 2005; Crant, 2000). However, in a recent study, Joo et al. (2015) noted a non-significant relationship between the same variables, in the context of South Korea.

Table 4: Summary of the Results

\begin{tabular}{lccl}
\hline Relationships & $\boldsymbol{\beta}$ & $\boldsymbol{p}$ & Results \\
\hline $\mathrm{PP} \rightarrow \mathrm{TI}$ & 0.14 & 0.06 & H1 is rejected \\
CSEs $\rightarrow$ TI & -0.24 & 0.00 & H2 is supported \\
$\mathrm{JC} \rightarrow \mathrm{TI}$ & -0.27 & 0.00 & H3 is supported \\
POS $\rightarrow$ TI & -0.28 & 0.00 & H4 is supported \\
$\mathrm{DFB} \rightarrow \mathrm{TI}$ & -0.24 & 0.00 & H5 is supported \\
\hline
\end{tabular}

Note: "CSE= core self-evaluations, $\mathrm{PP}=$ proactive personality, $\mathrm{POS}=$ perceived organizational support, $\mathrm{DFB}=$ developmental feedback, JC= job complexity, $\mathrm{TI}=$ turnover intention, $\mathrm{N}=359$ ".

Considering the contextual factors, this study assumed a negative association between POS and TI. This study found that individuals prefer to stay in those organizations where they feel that their organization cares for their values, and will help them at the time of need $\left(\beta=-0.28^{* *}\right)$. These results are further supported by OST of Eisenberger et al. (1986), and SET of Blau (1964). In addition, JC was found to have a negative relationship 
with TI $\left(\beta=-0.27^{* *}\right)$. This result is supported by Hackman and Oldham's (1980) job characteristics model, which states that when knowledgeable individuals consider their job more challenging, they tend to stay with the organization in order to prove their abilities and skills. However, while examining the alternate model, the study found a non-significant association between the same variables. Though the alternate model is rejected in this study due to the values of the goodness-of-fit indices, the model further needs to be examined in other geographical areas and less knowledgeable workers. Finally, the study found a negative association between developmental feedback and turnover intention $\left(\beta=-0.24^{* *}\right)$. Individuals in an organization need motivation and helpful feedback for their grooming and development, and when they receive useful information from their supervisors they not only complete their tasks diligently but also prefer to stay with the organization (Li et al., 2011).

The study has theoretical contributions as well. It integrates the contextual (POS, JC, and DFB) and personal (PP and CSEs) aspects in order to explain employees' intention to leave the organization. Despite being in debate for more than six decades, researchers have only focused on the attitudinal and behavioral predictors of turnover intention (i.e. satisfaction, commitment, citizenship behavior, stress etc.) e.g. (Morf, Arnold, \& Staffelbach, 2014; Schoemmel \& Jønsson, 2014). Nevertheless, both personal and contextual aspects have not been examined.

\section{Implications}

This is the first study of its kind to examine the association between PP and TI in Pakistani universities. Pakistani culture is marked by high power distance, collectivism, long-term orientation and uncertainty avoidance; distinguishing it from the Western counterparts, this culture that has largely been discussed in published literature. In the Pakistani society, people are mostly supportive, helpful, harmonious and polite.Iis, therefore, understood that proactive behaviors are discouraged here (Hakim \& Aziz, 1998). The cultures where proactive behaviors are discouraged, an employee may be less likely to interact with his/her supervisors/head of department (Joo, Yang, \& McLean, 2014). In addition to this, empirically investigating the impact of proactive personalities in different cultures, can contribute towards the understanding of the HRD at the international level. 
Earlier studies on turnover intention have suggested implications for the HR managers as they have to hire new employees in case of high turnover (Ahmad \& Allen, 2015). The procedure of recruitment and selection costs an organization ten times higher than retaining an employee. Moreover, the newly employed employee needs the training in order to understand the work ethics and getting best out of these newly recruited individuals. Therefore, this study has implications for both the HR departments, and the HRD professionals, and suggests that leadership practices (i.e. developmental feedback) and organizational cultural aspects (i.e. perceived organizational support) leads an employee towards better performance. Moreover, job complexity may be a greater source of retaining employees. This is so because such practices may lead to increased perceptions of job enrichment and de-jobbing, that result in a positive perception about the organization and job, resulting in positive job outcomes and reduced negative consequences like stress (Hargrove, Becker, \& Hargrove, 2015). Moreover, regular training and development programs should be arranged for the faculty members so as to enhance their abilities to give timely feedback to their subordinates.

Although this study found a small effect of core self-evaluations in predicting an employee's turnover intention, this variable should have been considered by a selection board at the time of recruitment and selection. The reason for this is that this particular variable is a part of ones' self-image, and it leads to positive attitudes and behaviors (e.g. reduced turnover intention). Thus, the selection considering core self-evaluations not only reduces the employee's intention of leaving the organization (Wagstaff et al., 2015) but also saves further training and hiring costs.

\section{Limitations and Future Research Directions}

Despite having the above stated implications, this study is not free from its limitations. Firstly, the data in the current study was collected at a single point in time (i.e. cross-sectional), which restricted the researcher to develop causal relations. Secondly, the respondents of the present study were highly knowledgeable, so the results could be knowledge biased. Thirdly, the majority of the respondents in this study were male faculty members. In addition to this, this study was conducted in the situation of economic conjecture, where people did not have the opportunities to find alternate jobs, and had to stick with their current challenging jobs. 
Examining the alternate model, the study found a non-significant association between JC and TI, which further needs to be generalized. Furthermore, how social support impacts an individual's withdrawal behavior should also have been examined, as this is supported by the theory of conservation of resources (Hobfoll, 1989). As of now, this study aimed to focus on less investigated antecedents (i.e. personal and contextual) of turnover intention as retaining talented faculty members has become a great challenge for the Pakistani private sector universities. The study found core self-evaluations, job complexity, developmental feedback and perceived organizational support as successful predictors of turnover intention. While the results regarding proactive personality and turnover intention further need to be generalized. This study also suggests that private universities should focus more on employees' supervision/head of the department, personal, job and contextual aspects in order to retain their faculty members. 


\section{References}

Ahmad, M., \& Allen, M. (2015). High performance HRM and establishment performance in Pakistan: An empirical analysis. Employee Relations, 37(5), 506-524.

Ahmad, R., \& Islam, T. (2018). Relationships between corporate social responsibility, work engagement and organizational commitment: Explanatory role of organizational identification. Journal of Behavioural Sciences, 28(2), 112-130.

Ahmed, I., Khairuzzaman Wan Ismail, W., Mohamad Amin, S., \& Islam, T. (2014). Role of perceived organizational support in teachers' responsiveness and students' outcomes: Evidence from a public sector University of Pakistan. International Journal of Educational Management, 28(2), 246-256.

Allen, D. G., Weeks, K. P., \& Moffitt, K. R. (2005). Turnover intentions and voluntary turnover: the moderating roles of self-monitoring, locus of control, proactive personality, and risk aversion. Journal of Applied Psychology, 90(5), 980-990.

Barrick, M. R., \& Mount, M. K. (1996). Effects of impression management and self-deception on the predictive validity of personality constructs. Journal of Applied Psychology, 81(3), 261-272.

Bateman, T. S., \& Crant, J. M. (1993). The proactive component of organizational behavior: A measure and correlates. Journal of Organizational Behavior, 14(2), 103-118.

Blau, P.M. (1964). Exchange and power in social life. New York: Wiley.

Byrne, B. M. (2010). Structural equation modeling with AMOS: Basic concepts, applications, and programming (2nd ed.). New York, NY, US: Routledge/Taylor \& Francis Group.

Chang, C.-H., Ferris, D. L., Johnson, R. E., Rosen, C. C., \& Tan, J. A. (2012). Core self-evaluations: A review and evaluation of the literature. Journal of Management, 38(1), 81-128. 
Chen, Y.-Y., \& Fang, W. (2008). The moderating effect of impression management on the organizational politics-performance relationship. Journal of Business Ethics, 79(3), 263-277.

Chung-Yan, G. A. (2010). The nonlinear effects of job complexity and autonomy on job satisfaction, turnover, and psychological wellbeing. Journal of Occupational Health Psychology, 15(3), 237-251.

Crant, J. M. (2000). Proactive behavior in organizations. Journal of Management, 26(3), 435-462. -

Eisenberger, R., Huntington, R., Hutchison, S., \& Sowa, D. (1986). Perceived organizational support. Journal of Applied Psychology, 71(3), 500-507.

Gouldner, A. W. (1960). The norm of reciprocity: A preliminary statement. American Sociological Review, 161-178.

Grebner, S., Semmer, N., Faso, L. L., Gut, S., Kälin, W., \& Elfering, A. (2003). Working conditions, well-being, and job-related attitudes among call centre agents. European Journal of Work and Organizational Psychology, 12(4), 341-365.

Griffeth, R. W., Hom, P. W., \& Gaertner, S. (2000). A meta-analysis of antecedents and correlates of employee turnover: Update, moderator tests, and research implications for the next millennium. Journal of Management, 26(3), 463-488.

Hackman, J. R., \& Oldham, G. R. (1980). Work redesign. Reading, Mass.: Addison-Wesley.

Hair, J., Black, W., Babin, B., \& Anderson, R. (2010). Multivariate data analysis (7th ed.): Upper saddle river (NJ): Prentice Hall.

Hair, J. F., Black, W. C., Babin, B. J., Anderson, R. E., \& Tatham, R. L. (2006). Multivariate data analysis ( $6^{\text {th }}$ ed.). Pearson Prentice Hall. New Jersey.

Hakim, A., \& Aziz, A. (1998). Socio-cultural, religious, and political aspects of the status of women in Pakistan. The Pakistan Development Review, 37(4), 727-746. 
Hargrove, M. B., Becker, W. S., \& Hargrove, D. F. (2015). The HRD eustress model: Generating positive stress with challenging work. Human Resource Development Review, 14(3), 279-298.

Hobfoll, S. E. (1989). Conservation of resources: A new attempt at conceptualizing stress. American Psychologist, 44(3), 513-524.

Humphrey, S. E., Nahrgang, J. D., \& Morgeson, F. P. (2007). Integrating motivational, social, and contextual work design features: a metaanalytic summary and theoretical extension of the work design literature. Journal of Applied Psychology, 92(5), 1332-1356.

Islam, T. (2014). Organizational learning culture and perceived organizational support as antecedents of employees' job related outcomes (Doctoral dissertation, Universiti Teknologi Malaysia).

Islam, T. (2019). Motivation to transfer training in learning organizations. Journal of Management Development, 38(4), 273-287.

Islam, T., Ahmad, U. N. B. U., Ali, G., Ahmed, I., \& Bowra, Z. A. (2013). Turnover intentions: The influence of perceived organizational support and organizational commitment. Procedia - Social and Behavioral Sciences, 103(2013), 1238-1242.

Islam, T., Ahmad, R., Ahmed, I. and Ahmer, Z. (2019). Police work-family nexus, work engagement and turnover intention: Moderating role of person-job-fit. Policing: An International Journal, 42(5), 739-750.

Islam, T., Ahmed, I., \& Ahmad, U. N. B. U. (2015). The influence of organizational learning culture and perceived organizational support on employees' affective commitment and turnover intention. Nankai Business Review International, 6(4), 417-431.

Islam, T., Khan, S. U. R., Ahmad, U. N. B. U., Ali, G., \& Ahmed, I. (2014). Organizational learning culture and psychological empowerment as antecedents of employees' job related attitudes: a mediation model. Journal of Asia Business Studies, 8(3), 249-263. 
Islam, T., \& Tariq, J. (2018). Learning organizational environment and extra-role behaviors: The mediating role of employee engagement. Journal of Management Development, 37(3), 258-270.

Joo, B.-K., Hahn, H.-J., \& Peterson, S. L. (2015). Turnover intention: The effects of core self-evaluations, proactive personality, perceived organizational support, developmental feedback, and job complexity. Human Resource Development International, 18(2), 116-130.

Joo, B.-K., \& Park, S. (2010). Career satisfaction, organizational commitment, and turnover intention: The effects of goal orientation, organizational learning culture and developmental feedback. Leadership \& Organization Development Journal, 31(6), 482-500.

Joo, B.-K., Yang, B., \& McLean, G. N. (2014). Employee creativity: The effects of perceived learning culture, leader-member exchange quality, job autonomy, and proactivity. Human Resource Development International, 17(3), 297-317.

Judge, T. A. (1997). The dispositional causes of job satisfaction: A core evaluations approach. Research in Organizational Behavior, 19, 151-188.

Judge, T. A., Erez, A., Bono, J. E., \& Thoresen, C. J. (2003). The core selfevaluations scale: Development of a measure. Personnel Psychology, 56(2), 303-331.

Kim, W., \& Hyun, Y. S. (2017). The impact of personal resources on turnover intention: The mediating effects of work engagement. European Journal of Training and Development, 41(8), 705-721.

Lee, G. T., \& Cho, J. G. (2013). A study on the relationship between human resources flexibility, job instability, and turnover intention in hotel enterprises. Tourism Research, 28(1),153-171.

Li, N., Harris, T. B., Boswell, W. R., \& Xie, Z. (2011). The role of organizational insiders' developmental feedback and proactive personality on newcomers' performance: An interactionist perspective. Journal of Applied Psychology, 96(6), 1317-27. 
Lyons, P. R. (2015). Core self-evaluation can help in making better recruitment and selection choices: It is economical and easy to use and gives a useful new dimension. Human Resource Management International Digest, 23(3), 17-19.

Man, D. C., \& Lam, S. S. (2003). The effects of job complexity and autonomy on cohesiveness in collectivistic and individualistic work groups: a cross-cultural analysis. Journal of Organizational Behavior, 24(8), 9791001.

March, J. G., \& Simon, H. A. (1958). Organizations. John Wiley \& Sons: New York.

Mobley, W. H. (1977). Intermediate linkages in the relationship between job satisfaction and employee turnover. Journal of Applied Psychology, 62(2), 237-240.

Mobley, W. H., Horner, S. O., \& Hollingsworth, A. T. (1978). An evaluation of precursors of hospital employee turnover. Journal of Applied Psychology, 63(4), 408-414.

Mor Barak, M. E., Nissly, J. A., \& Levin, A. (2001). Antecedents to retention and turnover among child welfare, social work, and other human service employees: What can we learn from past research? A review and metanalysis. Social Service Review, 75(4), 625-661.

Morf, M., Arnold, A., \& Staffelbach, B. (2014). The double psychological contracts of temporary agency workers. Employee Relations, 36(6), 708-726.

Park, R. (2019). Responses to emotional exhaustion: do worker cooperatives matter? Personnel Review, 48(2), 438-453.

Parker, S. K., Williams, H. M., \& Turner, N. (2006). Modeling the antecedents of proactive behavior at work. Journal of Applied Psychology, 91(3), 636-652.

Porter, L. W., \& Steers, R. M. (1973). Organizational, work, and personal factors in employee turnover and absenteeism. Psychological Bulletin, 80(2), 151-176. 
Schoemmel, K., \& S. Jønsson, T. (2014). Multiple affective commitments: quitting intentions and job performance. Employee Relations, 36(5), 516-534.

Seibert, S. E., Crant, J. M., \& Kraimer, M. L. (1999). Proactive personality and career success. Journal of Applied Psychology, 84(3), 416-427.

Wagstaff, M. F., del Carmen Triana, M., Kim, S., \& Al-Riyami, S. (2015). Responses to discrimination: Relationships between social support seeking, core self-evaluations, and withdrawal behaviors. Human Resource Management, 54(4), 673-687.

Wu, C.-H., \& Griffin, M. A. (2012). Longitudinal relationships between core self-evaluations and job satisfaction. Journal of Applied Psychology, 97(2), 331-342.

Zhou, J. (2003). When the presence of creative coworkers is related to creativity: role of supervisor close monitoring, developmental feedback, and creative personality. Journal of Applied Psychology, $88(3), 413-422$. 
